\title{
APORTES DEL PENSAMIENTO DE BERNARD LONERGAN A LA FUNDAMENTACIÓN DE LOS DERECHOS HUMANOS
}

\author{
Louis Roy, O.P. \\ Boston College (EE.UU.)
}

\section{Resumen}

En este artículo se intenta una fundamentación de los derechos humanos desde la perspectiva de Bernard Lonergan. La universalidad de éstos está cimentada en la naturaleza humana, que es dinámica, operante e histórica. La intencionalidad humana busca la objetividad, desplegando su poder en cuatro niveles: la experiencia, la comprensión, el juicio y la acción. De este dinamismo se desprenden cuatro preceptos: sé atento, sé inteligente, sé razonable y sé responsable. El descubrimiento del valor de estos imperativos fundamenta y salvaguarda los derechos humanos. Su desconocimiento engendra la distorsión del ser humano. Para corregir las desviaciones debe haber conversiones intelectuales, morales y religiosas, las cuales suponen la fe, ya que ésta permite reconocer con más claridad los valores.

\section{Palabras clave}

Derechos humanos, naturaleza humana, intencionalidad, valor, conversión, fe.

\section{Abstract}

In this article Louis Roy tries a fundamentation of human rights from the perspective of B. Lonergan. The universality of these is laid on the human nature, as dynamical, operating and historical. The human intentionality looks for the objectivity, unfolding its power in four levels: experience, understanding, judgment and action. From this dynamism there come out four rules: be kind, be intelligent,be reasonable and be responsible. The discovery of the value of these considerations bases and safeguards the human rights. 
Its ignorance generates the distortion of the human being. In order to correct the deviations, intellectual, moral and religious conversions are due to be given, which suppose faith, since it allows to recognize values more clearly.

\section{Key words}

Human rights, human nature, intentionality, values, conversion, faith.

El jesuita canadiense Bernard Lonergan (1904-84) siempre estuvo preocupado por el acontecer mundial. Toda su vida tuvo gran interés por aquellas inquietudes que luego la teología latinoamericana de la liberación adoptaría. Su pensamiento fue marcado por la crisis económica de los años treinta. Durante los años cuarenta, escribió sobre la difícil situación de los pescadores, la conservación de la vida rural, y problemas muy concretos como los certificados de ahorro en Canadá o las donaciones para alimentar a los niños que fueron evacuados desde Gran Bretaña ${ }^{1}$. En 1944 completó su primer manuscrito sobre economía, tema al cual regresó en 1975 contemplando su dimensión ética² ${ }^{2}$.

Quizá es sorprendente el hecho que Lonergan nunca escribió sobre los derechos humanos. Una razón para ello es que durante su carrera como profesor de teología dogmática nunca enseñó esta materia. Otra razón tiene que ver con el hecho de que a Lonergan no le gustaba el conceptualismo estático que generalmente cabe en el concepto de derecho, tal como sugiere plausiblemente John Haughey $^{3}$. No obstante su silencio sobre el área de los derechos humanos, Lonergan ofrece aportes significativos para fundamentar y fortalecer la legitimidad y la practicalidad de dichos derechos ${ }^{4}$. Un ex profesor de jurisprudencia en Washington escribe: “Aunque Lonergan no se preocupó directamente por los asuntos específicos relacionados con las normas éticas o legales, algunos moralistas han hallado inspiración y guía en su paradigma en el momento de reflexionar sobre la ley natural y las enseñanzas morales asociadas con esta ley"5.

\section{Una naturaleza humana dinámica}

Podemos decir que implícitamente en Lonergan los derechos humanos están cimentados en la naturaleza humana. Apoyándose

1 Ver Frederick E. Crowe, "Bernard Lonergan and Liberation Theology”, Appropriating the Lonergan Idea, ed. Michael Vertin (Washington, DC: The Catholic University of America Press, 1989), pp. 116-126; o “Bernard Lonergan y la teología de la liberación”, Humanidades (Annuario) 8 (1984-85), pp. 11-23.

2 Ver Collected Works of Bernard Lonergan, University of Toronto Press, vol. XV: Macroeconomic Dynamics: An Essay in Circulation Analysis, eds. Frederick G. Lawrence, Patrick H. Byrne y Charles Hefling, Jr., 1999; y vol. XXI: For a New Political Economy, ed. Philip J. McShane, 1998.

3 John C. Haughey, “Responsibility for Human Rights: Contribution from Bernard Lonergan”, Theological Studies 63 (2002), p. 774.

4 Recomiendo un sustancial artículo de Francisco Quijano, "El método trascendental en teología”, Liberación y Cautiverio: Debates en torno al método de la teología en América Latina, Encuentro latinoamericano de teología, agosto, 1975 (México, D.F.: 1976), pp. 375-408.

5 David Granfield, The Inner Experience of Law: A Jurisprudence of Subjectivity (Washington, D.C.: The Catholic University of America Press, 1988), p. 209. Este libro está influenciado firmemente por la filosofía de Lonergan. 
en Aristóteles, Lonergan ve aquella naturaleza como physis, es decir un principio de movimiento y de reposo. Su concepción de naturaleza es inspirada no sólo por Aristóteles, sino también por Tomás de Aquino. El planteamiento de Santo Tomás no es de manera alguna estático, pues comienza su explicación de la ley natural a partir de tres tendencias humanas. En la Suma Teológica, I-II, cuestión 94, artículo 2, sobre la ley natural, él propone el siguiente principio: "el orden de los preceptos de la ley natural es correlativo al orden de las inclinaciones naturales”. Enseguida enumera fenomenológicamente, aunque de manera breve, tres inclinaciones humanas:

Y así encontramos, ante todo, en el hombre una inclinación que le es común con todas las sustancias, consistente en que toda sustancia tiende por naturaleza a conservar su propio ser. Y de acuerdo con esta inclinación pertenece a la ley natural todo aquello que ayuda a la conservación de la vida humana e impide su destrucción. En segundo lugar, encontramos en el hombre una inclinación hacia bienes más determinados, según la naturaleza que tiene en común con los demás animales. Y a tenor de esta inclinación se consideran de ley natural las cosas que la naturaleza ha enseñado a todos los animales, tales como la conjunción de los sexos, la educación de los hijos y otras cosas semejantes. En tercer lugar, hay en el hombre una inclinación al bien corres- pondiente a la naturaleza racional, que es la suya propia, como es, por ejemplo, la inclinación natural a buscar la verdad acerca de Dios y a vivir en sociedad. Y, según esto, pertenece a la ley natural todo lo que atañe a esta inclinación, como evitar la ignorancia, respetar a los conciudadanos y todo lo demás relacionado con esto $^{6}$.

Lonergan desarrolló el aspecto antropocéntrico del pensamiento de Santo Tomás ${ }^{7}$. $\mathrm{Al}$ igual que el gran doctor medieval, este importante pensador del siglo $\mathrm{XX}$ ve la naturaleza humana a partir de una perspectiva dinámica ${ }^{8}$. Aquí se nota una diferencia significativa con la perspectiva moderna que, siguiendo a Descartes, tiene su base en la lógica. Por ejemplo, el imperativo categórico de Kant no cubre mucho terreno porque demanda la universalización; es decir, la exigencia de universalidad para toda conducta obligatoria: “Obra sólo según aquella máxima de la que al mismo tiempo puedas querer que se convierta en norma universal”"9.

Consecuentemente, por un lado los imperativos de Kant, aunque básicos, son muy pocos: respeto a su vida propia (no suicidio), fidelidad a sus promesas (no mentira), fomento de los talentos propios (no pereza), y ayuda a la gente en necesidad (no indiferencia). Por otro lado, Kant tiene el mérito de fundamentar la dignidad de la persona como un fin y no como un medio, y de reconocer su autonomía.

\footnotetext{
Utilizo la traducción de la Biblioteca de Autores Cristianos, Madrid, 1989.

Ver Johannes Baptist Metz, Christliche Anthropozentrik: Über die Denkform des Thomas von Aquin (Munich: Kösel Verlag, 1962).

8 Mauricio Beuchot Puente también propone una opción por un iusnaturalismo tomista renovado en Los derechos humanos y su fundamentación filosófica (México, D.F.: Universidad Iberoamericana, 1997).

9 Immanuel Kant, Cimentación de la metafísica de las costumbres, trad. Carlos Martín Ramírez, 4a. ed. (Buenos Aires: Aguilar, 1976) p. 100. Ver Akademie, p. 421, y, por el resto de mi párrafo, Akademie, pp. 422-423, 429, 431.
} 
Por el contrario, Lonergan encuentra la universalidad de la naturaleza humana y su expresión como derecho natural, no en proposiciones autoevidentes o en certidumbres innatas, sino en dicha naturaleza como operante concretamente; es decir, como historicidad ${ }^{10}$. En lo que resta de este ensayo, veremos que el conocimiento que Lonergan brinda sobre dicha naturaleza se desarrolla empíricamente y puede ser verificado por todos.

\section{Una subjetividad en busca de objetividad}

No obstante su desacuerdo con Descartes y Kant, Lonergan acepta el giro hacia el sujeto que caracteriza la filosofía moderna. Bajo la influencia de Brentano y Husserl, habla de intencionalidad. Esta es la subjetividad humana en busca de objetividad, dinámicamente abierta y orientada a la realidad. El descubrimiento de sus operaciones fundamentales y valores de base fundamenta y salvaguarda los derechos humanos.

Para describir los constitutivos intrínsecos de la intencionalidad, Lonergan utiliza la metáfora de cuatro niveles. En el nivel de la experiencia, la intencionalidad recibe los datos de los sentidos. Segundo, en el nivel de la comprensión, surge la pregunta “¿qué es?” (o “¿por qué?” “¿cómo?”); resulta una idea, o concepto, o hipótesis. Tercero, en el nivel del juicio, surge la pregunta "¿es eso así como lo he entendido?”; resulta un compromiso intelectual. Cuarto, en el nivel de la acción, surge la pregunta "¿es eso realmente valioso?” y “¿vale la pena hacerlo?”; resulta un juicio de valor y un comportamiento.

Con relación a dichos cuatro niveles de intencionalidad, los derechos humanos están basados en cuatro preceptos trascendentales: sé atento, sé inteligente, sé razonable, sé responsable. Estos cuatro imperativos exigen un respeto hacia la realidad, la cual es a la vez realidad de la naturaleza (los seres infrahumanos) y realidad del género humano (las personas).

Los derechos humanos son numerosos. No hay una lista definitiva de ellos. Sin embargo, la implementación de los preceptos trascendentales inicia la acumulación de documentos relevantes, la comprensión, las verificaciones y los juicios de valores. Todas esas actividades son dinámicas y posibilitan acciones responsables. Por ejemplo, cuando un derecho entra en conflicto con otro, los cuatro niveles de esta intencionalidad permiten una búsqueda que alcanza una evaluación comparativa con un grado variable de probabilidad.

Asimismo nos preguntamos: ¿Qué son los derechos inherentes e inalienables? ¿Son valiosos todos los derechos legalmente publicados? Todavía la intencionalidad es el referente crítico. Los juicios que la gente tiene deben ser considerados. Además, los juicios de los juristas e intelectuales pueden criticar el instrumental ideológico en uso. Las leyes tienen que concretar exigencias anteriores, más básicas; es decir, las del derecho natural. La filosofía de Lonergan descarta el voluntarismo del positivismo jurídico, según el cual los derechos derivan de decisiones legales (que a veces son expresiones de la voluntad arbitraria por parte de quienes ejercen el poder).

Por ser más que decisiones legales, los derechos demandan que una sociedad entera (o una porción mayoritaria) crea y participe lo más armoniosamente posible en los valores. Lonergan enfatiza una escala ascendente de valores: vitales, sociales, culturales, perso-

10 "Natural Right and Historical Mindedness", A Third Collection: Papers by Bernard Lonergan, ed. Frederick E. Crowe (New York: Paulist Press, 1985), pp. 169-183. 
nales y religiosos. Noten los lectores que los "niveles” de esta escala no son los "niveles" trascendentales. Consuelo Vélez presenta claramente los cinco niveles de los valores:

El primer nivel es el de los valores vitales. Éstos son las condiciones básicas para vivir: salud, alimento, casa, trabajo, etc. El segundo nivel corresponde a los valores sociales. El ser humano, como ser en sociedad, necesita organizarse y establecer una cooperación con otros para conseguir el bien común. No se garantiza la vida solamente para sí mismo, sino también para todos. En el tercer nivel encontramos los valores culturales. El ser humano da significado a su actuar y su sentir. Los dos primeros niveles dan el contenido a este nivel, y el tercer nivel ilumina, fortalece y propicia un discernimiento adecuado al vivir y operar humano, buscando el bien más grande y valioso. El cuarto nivel es el nivel de los valores personales. Cada uno de nosotros vale por el hecho de ser persona. La capacidad humana de amar y ser amado ofrece el valor personal que se convierte en invitación para crear redes de solidaridad y justicia para todos. En el quinto nivel se sitúan los valores religiosos que corresponden a la apertura trascendente que el ser humano descubre en sí mismo y que lo invita a ese tender radical, ese tender irrestricto, del experimentar al entender, del entender al juzgar, del juzgar al discernir, del discernir al amar ${ }^{11}$.

De este modo, gracias a la apropiación de sus cuatro niveles de operaciones fundamentales y de su escala de valores, un filósofo logra una conciencia filosófica, no más compacta, sino más diferenciada.

\section{Una humanidad sesgada}

No es fácil respetar los valores inferiores, es decir, los vitales y sociales. Explica Vélez:

El egoísmo individual y de grupo prefiere las ganancias personales a la opción por lo realmente bueno y valioso. Esos egoísmos son la base de la situación de injusticia estructural. El lucro conseguido por unos se hace a costa de la opresión y miseria de los otros. El bien de los valores vitales y sociales para todos queda olvidado en función del bien individual o de pequeños grupos ${ }^{12}$.

Igualmente, el desconocimiento de los valores superiores, esto es, los culturales, personales y religiosos, engendra una distorsión del ser humano.

En Insight ${ }^{13}$, Lonergan describe cuatro tipos de desviación (bias, sesgo): la aberración dramática, la aberración individual, la aberración de grupo, y la aberración general. Pondremos de relieve el primero y el cuarto tipo, porque el pensamiento de Lonergan es más original sobre estos tipos que sobre la desviación individual y la desviación de grupo.

La aberración dramática se coloca entre la psiquis y el entendimiento. Ella consiste en una escotosis (griego: skotosis, oscurecimiento). Lonergan escribe: "Fundamentalmente, la escotosis es un proceso inconsciente. Se presenta no en los actos conscientes, sino en la función de censura que gobierna

11 Olga Consuelo Vélez Caro, El método teológico: Bernard Lonergan y la teología de la liberación, 3a. ed. (Bogotá: Pontificia Universidad Javeriana, 2004), p. 195.

12 Vélez, El método..., pp. 284-285.

13 Bernard Lonergan, Insight: Estudio sobre la comprensión humana, trad. Francisco Quijano (México, D.F.: Universidad Iberoamericana; Salamanca: Ediciones Sígueme, 1999), pp. 243-246, 276-295. 
el surgimiento de los contenidos psíquicos. Sin embargo, el proceso no es del todo oculto para nosotros"14. Como veremos, hay posibilidades de superar la escotosis.

Él describe la escotosis en términos de represión e inhibición. En primer lugar, represión:

La escotosis es una aberración no sólo de la comprensión, sino también de la función de censura. Así como desear un acto de intelección penetra a través de la superficie para gestar ciertas imágenes esquemáticas que propician el surgimiento del acto de intelección, asimismo no desear una intelección tiene el efecto contrario de suprimir de la consciencia un esquema que propiciaría el acto de intelección (...). En cambio, la aberración de la función de censura es primordialmente represiva: su actividad positiva consiste en impedir la aparición en la conciencia de perspectivas que propiciarían el surgimiento de actos de intelección no deseados; introduce, por decirlo así, la exclusión de ordenamientos dentro del campo del inconsciente ${ }^{15}$.

En segundo lugar, inhibición:

El efecto de la represión es una inhibición impuesta a las funciones neurales de demanda. Sin embargo, si distinguimos entre las demandas de imágenes y las demandas de afectos, queda claro que la inhibición no obstruirá ambas de la misma manera. Pues las intelecciones surgen, no de la experiencia de afectos, sino más bien de las presentaciones imaginativas. Por tanto, para impedir las intelecciones, la represión tendrá que inhibir ciertas demandas de imágenes. Por otra parte, necesita inhibir ciertas demandas de afectos únicamente si están asociadas a las imágenes no deseadas ${ }^{16}$.

La desviación individual y la desviación grupal no necesitan explicaciones largas. Las describiré sucintamente ${ }^{17}$. Lonergan llama “aberración individual” al egoísmo que consiste en no reconocer las limitaciones de los intereses propios. De hecho, el individuo adolece de un desarrollo incompleto de su inteligencia, pues niega su orientación hacia el bien común. Él rechaza las preguntas e intelecciones que podrían aclarar la relevancia de las necesidades de los demás.

La “aberración de grupo” es el mismo fenómeno en un plano más amplio. Ocurre cuando los intereses de dos o más grupos antagónicos chocan, cada uno con sus mecanismos ofensivos y defensivos. Un grupo o una clase usa su razón práctica y su poder para explotar, manipular, dominar, coercer y marginar otros grupos o clases. De acuerdo con Lonergan, una tensión puede convertirse en una dialéctica, la cual, en Insight tiene una connotación negativa. Por lo tanto, la tensión natural e inevitable entre los deseos, gozos, privaciones y sufrimientos del individuo y su inteligencia abierta a las exigencias prácticas de situaciones objetivas, puede culminar en una dialéctica social que es no natural, evitable, pero perjudicial.

La cuarta desviación es llamada “aberración general”18. Está arraigada en el sentido común. Cada cultura o subcultura tiene su sentido común; es decir, su horizonte de cono-

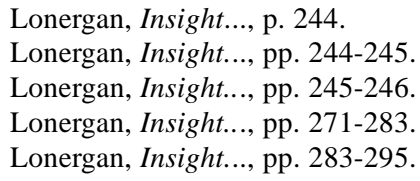


cimientos e intereses. No obstante las enormes diferencias, todas las formas de sentido común sufren de una carencia fundamental: el sentido común está esencialmente centrado en comportamientos y no interesado en cuestiones teóricas. Por consiguiente, resiste de manera casi inevitable las preguntas e ideas que contradicen sus opiniones favoritas. Además, considera como normales los hechos sociales absurdos. Porque está cerrado en su horizonte práctico y carece de capacidad crítica, sólo ve los resultados inmediatos y descuida las consecuencias a largo plazo. Mientras que la desviación de grupo produce daños de alcance relativamente limitado, la desviación general sostiene un ciclo más amplio de decadencia. Finalmente, sin revelación cristiana, el sentido común no puede tomar conciencia de los límites intrínsecos de su practicalidad.

\section{Una solución compleja}

Consciente de los tipos de desviación, Lonergan no acepta la solución del liberalismo político. Hablando de autointerés iluminado, los editores de su ensayo sobre economía escriben: "El significado de esto tiende a ser el determinar cómo la preocupación por el interés del otro representa una ventaja para uno. De acuerdo con Lonergan, esto no representa la superación de las aberraciones que es necesaria para vencer el decline social y cultural”'

Otra estratagema que Lonergan rechaza es diseñar técnicamente el bienestar humano. Él desaprueba "la implacable tendencia moderna a la ingeniería social y los controles totalitarios”20. Lonergan denuncia las mani- pulaciones de los tecnócratas: "el simple hecho de organizar personas no implica que sean tratadas como personas. Para tratarlas como personas uno tiene que conocer e invitarles a conocer"21. Debido al énfasis que pone en el deseo radical de saber, Lonergan considera a los seres humanos no como sujetos pasivos, que deberían recibir sin discusión alguna las decisiones tomadas en su ausencia por aquellos que mantienen el poder. Al contrario, son participantes y gestores de su historia y, como tales, tienen el derecho de tomar las riendas de su propio destino. El reconocimiento del carácter activo y libre de las personas y grupos es el primer paso hacia una superación de las desviaciones.

Concretamente, él quiere decir que, por encima del respeto físico debido a los seres humanos, es preciso cultivar un respeto más profundo: respeto por la cultura (sin negar sus deficiencias) de las comunidades que viven en una posición de debilidad política. Se necesita atención a su vida familiar, vínculos intersubjetivos, relaciones de vecindario, condiciones de trabajo, habilidades, valores, costumbres, compromisos. También esto supone medios y estructuras de comunicación, libertad para elegir sus líderes, tomar decisiones y escuchar la voz de las víctimas. Por consiguiente, la esfera de los derechos no es un enclave reducido, una zona de concesiones para temperar el rigor de la economía y de la política.

De esta manera, la razón práctica de una comunidad es ejercida por varios agentes. La filosofía de Lonergan excluye la tendencia privatista del mercado mundial. En contraste con esta corriente deshumanizante, su fi-

19 Lonergan, "Editors Introduction”, Macroeconomic Dynamics..., lxx.

20 Lonergan, Insight..., p. 852.

21 Bernard Lonergan, “Cognitional Structure”, Collected Works of Bernard Lonergan, vol. IV: Collection, eds. Frederick E. Crowe y Robert M. Doran (Toronto: University of Toronto Press, 1988), pp. 220-221. 
losofía es comunitarista ${ }^{22}$. Lonergan propone un cierto comunitarismo, moderado por el acento sobre la relación de cada individuo con el Trascendente. Además, su versión de la igualdad no es abstracta, como en Kant, sino enriquecida por su comunitarismo interpersonal.

Tres conversiones tratan de suplir las lagunas de dichas desviaciones ${ }^{23}$. La conversión intelectual consiste en una autoapropiación de los procesos cognoscitivos, los cuales son escalonados según los tres primeros niveles de intencionalidad. El individuo convertido intelectualmente entiende que la objetividad no es cuestión de mirar bien lo que está “ya afuera allí ahora real”24; más bien, es cuestión de ir más allá de lo imaginativo hasta lo espiritual, lo que caracteriza los insights y los juicios. Una metafísica correcta del ser procede de este descubrimiento epistemológico.

Las otras dos conversiones conllevan a un importante cambio de actitudes en el cuarto nivel de intencionalidad. La conversión moral exige no solamente un desarrollo horizontal, sino también una elevación o ejercicio vertical de la libertad humana, que acepta y sostiene consistentemente la opción por los valores, aun cuando estos no sean compatibles con las satisfacciones. Así, una persona es capaz de respetar la jerarquía de los valores y de alcanzar la autenticidad.

La conversión religiosa es fruto de una experiencia muy especial: un estado dinámico de conciencia que consiste en estar enamo- rado sin restricciones ni reservas con el misterio. Dicha experiencia engendra la fe, que Lonergan define como "el conocimiento nacido del amor religioso" 25 .

Esta fe resulta ser de gran utilidad para la vida del mundo, pues reconoce los valores más claramente y, de cara al mal, acepta los sufrimientos requeridos para deshacerlo. Es una fuente de decisiones correctas y animosas que restituye la decadencia causada por el pecado. Los grupos animados por la fe, la esperanza y la caridad tienen la motivación para promover el bien común, favorecer el progreso y contrarrestar el decaimiento so$\mathrm{Cial}^{26}$. Con todo, nunca veremos un mundo perfecto. Puesto que la dialéctica de las posiciones en conflicto es permanente, siempre es necesario un esfuerzo valiente de parte de los que estudian los problemas y situaciones para analizarlos y buscar rectificaciones y mejoramientos.

\section{Conclusión}

En suma, la concepción que Lonergan diseña sobre el ser humano y su vida en sociedad ubica bien los recursos, los problemas y los remedios de una praxis de los derechos esenciales. Es una base epistemológicaantropológica que hace reconocer y brotar los derechos humanos. En efecto, la base epistemológica es la naturaleza humana observable en sus dinamismos invariables, es decir, los cuatro niveles de intencionalidad con sus preceptos trascendentales. Además, la base antropológica explica las distorsiones

\footnotetext{
22 Ver Francisco Sierra Gutiérrez, “La comunidad como sujeto”, Universitas Philosophica, 39.19 (2002), pp. 79-118.

23 Lonergan, Método en teología, trad. de Gerardo Remolina (Salamanca: Ediciones Sígueme, 1988), pp. 232-235.

24 Ver Lonergan, Insight..., Indice de materias y autores, “Real”, p. 930.

25 Lonergan, Método..., p. 116.
} 
que afectan dichos dinamismos. Más aún, Lonergan propone algunas soluciones: la educación $^{27}$; varias psicoterapias ${ }^{28}$; los recursos del humor, la ironía y la sátira (ya empleados por Kierkegaard) en las artes, en la literatura y en los medios de comunicación, para detectar las aberraciones ${ }^{29}$; el hecho de que todo proceso de aberración pronunciada es insoportable y así crea los principios de su propia reversión, gracias a las sanas reac- ciones de la razón crítica y de la cultura ${ }^{30}$; la colaboración interdisciplinaria de personas competentes para examinar y revisar los proyectos políticos e implementar una “cosmópolis”, es decir, una cooperación libre y reformadora a escala global ${ }^{31}$; la influencia de "las formas conjugadas" que son la fe, la esperanza y la caridad ${ }^{32}$, en el combate para el bien común y contra el mal ${ }^{33}$.

26 Lonergan, Método..., pp. 117-118.

27 Bernard Lonergan, Filosofía de la educación: Las conferencias de Cincinnati en 1959 sobre aspectos de la educación, trad. Armando J. Bravo G. (México, D.F.: Universidad Iberoamericana, 1998).

28 Lonergan, Insight..., pp. 253-257.

29 Lonergan, Insight..., pp. 719-722.

31 Lonergan, Insight..., pp. 297-302; Método ..., p. 351.

32 Lonergan, Insight..., pp. 799-835.

33 Agradezco a Hosffman Ospino por su ayuda en la edición de este texto en español. 